\title{
CIÊNCIAS SOCIAIS EM SAÚDE, EDUCAÇÃO MÉDICA E A CONCEPÇÃO INTERVENCIONISTA E COLONIAL DA PRÁTICA MÉDICA
}

\author{
SOCIAL SCIENCE IN HEALTH, MEDICAL EDUCATION AND THE INTERVENTIONIST \\ AND COLONIAL CONCEPTION OF MEDICAL PRACTICE
}

\author{
CIENCIAS SOCIALES EN SALUD, EDUCACIÓN MÉDICA Y LA CONCEPCIÓN \\ INTERVENCIONISTA Y COLONIAL DE LA PRÁCTICA MÉDICA
}

\author{
Rafael Afonso da Silva ${ }^{1}$ \\ Juan Carlos Aneiros Fernandez ${ }^{2}$ \\ Nelson Filice de Barros ${ }^{3}$ \\ Juliana Luporini do Nascimento ${ }^{4}$
}

Resumo A pesquisa apresentada neste artigo teve por escopo investigar a 'expressão de certa lógica' dominante na formação médica por meio da análise de expectativas colhidas de estudantes de uma instituição de ensino de medicina em relação a uma disciplina concentrada em temas/reflexões das ciências sociais em saúde e coordenada por cientistas sociais. O material analisado foi composto de expectativas de 72 estudantes coletadas por meio de um convite para escreverem livremente, sem necessidade de se identificar, sobre o que esperavam em relação à disciplina. A análise desse material revelou a dominância de discursos e experiências pedagógicas que contribuem para a produção de uma concepção 'instrumental' e 'colonial' da prática médica e permite compreender algumas dificuldades para o exercício crítico-reflexivo das ciências sociais no ensino médico. Ao identificar a necessidade de desconstrução dessa 'lógica', concluiu-se não com uma proposta pedagógica concreta, mas com a indicação da necessidade de um processo de desinstitucionalização/institucionalização orientado para 'descompressão' epistêmica do campo da saúde em geral e da educação médica em particular, uma abertura para outros agentes, outras epistemologias e para a possibilidade de novas conexões produtivas no campo da saúde e da medicina.

Palavras-chave ciências sociais; educação médica; colonialidade.

\begin{abstract}
The research presented in this article aims to investigate the 'expression' of certain dominant 'logic' in medical education by analyzing the expectancies of students of a medical teaching institution in relation to a discipline focused on topics/questions of social sciences in health and coordinated by social scientists. The material analyzed comprises expectations of 72 students collected by an invitation to write freely about what they expect from the discipline. The result shows the dominance of discourses and pedagogical experience that contribute to production of an 'instrumental' and 'colonial' conception of the medical practice and allows us to understand some difficulties to the critical-reflexive exercise of social science in the medical education. Identifying the need to deconstruct this 'logic', the article concludes not with a concrete pedagogical proposal, but with the indication of the need for a process of deinstitutionalization/ institutionalization oriented to epistemic 'decompression' of the field of health in general and medical education in particular, an opening to other agents, other epistemologies and to the possibility of new productive connections in the field of health and medicine.
\end{abstract}

Keywords social science; medical education; coloniality. 


\section{Introdução}

Nos estudos sobre as experiências pedagógicas do ensino de ciências sociais em cursos de medicina, é reconhecida, e de longa data, a influência da "cultura do estudante de medicina" sobre as possibilidades e os limites dessas experiências (Nunes, 1978, p. 513). No entanto, essa dimensão é vagamente referida nesses estudos, que se concentram, em geral, na análise das projeções teóricas e pedagógicas das propostas e modelos de ensino de ciências sociais na escola médica.

Apesar da carência relativa de pesquisas específicas relacionadas ao tema, a existência de uma barreira cultural é, de ordinário, relatada pelos profissionais e percebida como derivada, em parte, da internalização pelos estudantes de um 'currículo informal e oculto' que, ao estabelecer as fronteiras de legitimidade dos saberes dentro das instituições de ensino de medicina, sob a hegemonia de um modelo biomédico 'epistemologicamente entrincheirado', reserva às ciências sociais um lugar de baixo reconhecimento ou, pelo menos, de status oscilante (Litva e Peters, 2008; Barros, 2014). Contudo, o cenário talvez seja mais complexo.

Como pesquisas qualitativas empiricamente embasadas têm demonstrado, embora a hipótese da existência daquele 'currículo informal e oculto' não possa ser, de modo algum, descartada, é possível constatar, entre os estudantes de medicina, a presença de posições muito distintas em relação ao valor das ciências sociais (Satterfield et al., 2010) ou de percepções diferentes em relação aos "sentidos e valores agregados a suas experiências" em disciplinas concentradas em temas e reflexões orientados pelas ciências sociais (Barros et al., 2016, p. 148). Essa possibilidade de uma pluralidade de atitudes e percepções demanda uma reflexão mais profunda sobre os processos de subjetivação e a possibilidade de linhas de fuga divergentes dentro das instituições de ensino de medicina.

A literatura parece conduzir-nos, assim, a um 'lugar' ambivalente, entre uma confluência institucionalmente produzida e uma pluralidade renitente. É dialogando com essas possibilidades que produzimos este artigo.

Por iniciativa de seus docentes, têm sido periodicamente coletadas expectativas e avaliações dos alunos das duas disciplinas do módulo 'saúde e sociedade'. Pertencentes ao núcleo obrigatório do currículo do curso de Medicina da Faculdade de Ciências Médicas (FCM) da Universidade Estadual de Campinas (Unicamp), essas disciplinas, semestrais e sequenciais, dirigidas aos estudantes do segundo ano do curso, são as únicas voltadas para desenvolver diretamente temas e reflexões com base em abordagens das ciências sociais. Além disso, são as únicas disciplinas desse núcleo com propostas efetivamente elaboradas pelos profissionais da área de ciências sociais aplicadas à saúde da FCM. Em razão dessa disposição do arranjo curricular, as expectativas e avaliações dos discentes sobre tais disciplinas constituem um material valioso para examinar 
as atitudes e percepções dos estudantes de medicina em relação ao papel, ao sentido e ao valor das ciências sociais na formação médica.

Este artigo analisa uma fração pequena desse material: as expectativas colhidas na primeira disciplina do módulo 'saúde e sociedade' em um ano específico. A concentração sobre essa fração do material produz um determinado viés, pois, como temos constatado pela comparação entre expectativas e avaliações em diferentes anos, essas duas oportunidades são mobilizadas como loci para diferentes intencionalidades ou estratégias enunciatórias.

Em uma pesquisa avaliativa de programa de qualificação profissional para jovens, a análise de expectativas colhidas com os participantes, em dois momentos distintos, referiu dois tipos de resposta emergentes:

(...) no primeiro caso, a resposta pode prescindir da experiência vivida singularmente pelo bolsista e, no segundo caso, ocorre o oposto. A primeira resposta é a expressão de certa lógica; a segunda é a expressão de um sujeito (Fernandez, 2008, p. 132).

É algo semelhante a isso o que encontramos no cotejamento das expectativas e das avaliações. As 'primeiras' referem-se menos à 'expressão de um sujeito' do que à tentativa de um sujeito de alinhar suas expectativas realisticamente ao sentido que estudos de 'saúde e sociedade' poderiam ter no contexto de 'certa lógica', qual seja, do itinerário formativo trilhado na instituição ou do discurso que 'a instituição' (a 'lógica' sedimentada de discursos confluentes, dominantes na instituição) faz desse itinerário e de sua intencionalidade. É o que parece explicar a espantosa similaridade entre as expectativas colhidas. Já as 'avaliações' aparecem como um esforço de expressão da experiência concreta dos distintos sujeitos com a disciplina, experiência construída e elaborada na relação com contextos de interação e interlocução diversos, quer dizer, sob a influência de seus fluxos e sentidos e de seus dispositivos de controle e estratégias de subversão. Nesse sentido, expõem posicionamentos de diferentes sujeitos e permitem apreender a existência de distintos processos de subjetivação dentro da instituição - donde a grande diversidade que caracteriza as avaliações, quando comparadas às expectativas.

Para nós, interessou investigar tanto o conteúdo da 'lógica' que se repõe nas expectativas - apreendendo seu significado no que concerne a certo modo de entender e valorar o papel das ciências sociais ou dos estudos de 'saúde e sociedade' no curso de medicina - quanto a pluralidade de posicionamentos que emerge nas avaliações. Esse interesse decorreu da percepção de que ambas revelam algo acerca da instituição e da complexidade dos processos de subjetivação que ela abriga.

Este artigo deve, nesse sentido, ser lido como parte de uma investigação em curso e se inscreve na perspectiva de sua necessária complementação por um texto que aborde o segundo conjunto de materiais. 


\section{Análise das expectativas}

O material que se constituiu em objeto deste artigo é composto de expectativas de 72 estudantes do segundo ano do curso de medicina, as quais foram coletadas por meio de um convite para que eles escrevessem livremente, sem necessidade de se identificar, sobre o que esperavam em relação à disciplina.

Dados os objetivos dessa atividade, ela deve ser feita logo no primeiro dia de aula, antes de qualquer comentário sobre o programa da disciplina, a fim de que as expectativas possam expressar as interpretações, os posicionamentos e os desejos dos estudantes naquele momento de sua formação em relação a uma disciplina com a legenda de 'saúde e sociedade'. Há, contudo, um inconveniente para a realização dessa proposta, pois, no primeiro dia de aula, a frequência é sempre muito baixa e não é possível obter mais do que uma amostragem das percepções dos alunos sobre a disciplina. No ano selecionado para o estudo a que se refere este artigo, captamos 72 expectativas em uma turma de 120 alunos, ou seja, $60 \%$ do total.

Tal amostragem é, sem dúvida, significativa em termos percentuais, mas o que a torna mais confiável é o fato de que, nesse conjunto, encontramos, a despeito de matizes e ênfases diversificados, um núcleo de sentido prevalente que tem se repetido nas amostragens dos anos seguintes. Esse núcleo remete a sentidos e interesses construídos ao longo da experiência com o módulo 'ações de saúde pública', da grade curricular do primeiro ano do curso médico. Essa vinculação se exprime, em geral, na forma da demanda de 'mais', quer dizer, de continuação, ampliação ou intensificação - ou ainda, no caso de objetivos e interesses não satisfatoriamente realizados na visão do estudante, de suplementação ou correção.

Não é difícil, em uma leitura atenta do material, perceber a prevalência de três tipos de demandas interligadas. O primeiro tipo compreende as demandas de um 'melhor entendimento', 'uma visão mais próxima', 'realista', 'mais ampla' ou 'mais completa' de uma determinada 'realidade', concebida seja em uma escala social mais ampla, como 'a população', por exemplo, seja no plano das inter-relações mais diretas, como 'as pessoas', 'a realidade do paciente', 'a relação médico-paciente' etc. O segundo tipo abrange as avaliações que reclamam mais atividades 'práticas' ou 'mais contato' com as unidades básicas de saúde, com os usuários da atenção básica ou a população do território adscrito pelas unidades, muitas vezes, em oposição explicitada a abordagens pedagógicas que valorizem a prática de leitura e a discussão teórica. Já a terceira demanda é a de um aprendizado com sentido prático, traduzível em termos de técnicas, de parâmetros para a ação profissional futura ou para a ação imediata ('projetos de intervenção') em campos de aprendizado. 
Eis alguns exemplos representativos:

Na disciplina, eu espero compreender de forma mais completa o papel do médico na sociedade e a importância dele nesse meio. Espero também compreender, mediante a importância social, como seria a forma correta de abordar o paciente, de maneira a ser capaz de fornecer amparo emocional e médico a este paciente perante a sociedade em que está inserido (S1).

Eu espero com a disciplina que eu aprenda a relacionar a estrutura, os fatos e os acontecimentos sociais ao adoecimento. Aprenda também a identificar formas de mudar a sociedade para prevenir ou curar doenças (S2).

Eu espero desta disciplina aprender ainda mais sobre o Sistema Único de Saúde e sua relação com a sociedade de modo geral. Cumprindo ou não com suas obrigações públicas. Também espero que a disciplina discuta a sociedade e seu comportamento, de modo a analisar qual o melhor procedimento a tomar perante a população segundo suas necessidades epidemiológicas, saneamento básico ou simples atendimento médico (S3).

Eu espero que na disciplina eu possa ter mais contato com os pacientes, eu possa entender melhor, na prática, o funcionamento do sistema básico de saúde pública. Que eu consiga ter uma boa visão dos defeitos do sistema público de saúde e, junto com o grupo, criar propostas e projetos EFETIVOS para melhoria desse sistema (S4 - ênfase do aluno).

Eu espero que a disciplina possa representar uma continuação do nosso trabalho com os centros de saúde, de modo que seja possível continuarmos a conhecer a realidade desses centros e possamos interagir com seus funcionários e sua comunidade de maneira a contribuir da melhor maneira possível para seu bom andamento. Para isso, é bom melhorar de alguma forma o centro, desde sugestões até ações mais concretas (S5).

Eu espero que essa disciplina MD342 possa contribuir para o aprendizado permitindo que eu conheça e tenha contato com a população (...). E, desta forma, eu possa garantir, no futuro, tratamento e medidas adequadas com base nos costumes, tradições e deficiências da população. Espero ainda ter contato com a realidade da população para que crie medidas terapêuticas acessíveis para que meu atendimento seja da melhor qualidade (S6).

Desde logo, assoma desse conjunto de enunciados a conexão entre a intenção de 'compreender', 'aprender', 'entender' e uma determinada perspectiva de 'intervenção'. Trata-se de um 'compreender ou aprender para', que se estende ou se conecta imediatamente não somente a um 'agir', mas a um 'agir sobre', traduzido pelos verbos 'abordar', 'mudar', 'melhorar'. O sentido da aprendizagem é, assim, construído com base em um deslocamento já amplamente tematizado 
como algo próprio da 'razão instrumental': a libido sciendi (orientada para o conhecimento) é deslocada pela libido dominandi (orientada para o poder e o controle sobre aquilo que define como seu objeto) (Maffesoli, 1998). Por outro lado, ao mesmo tempo, o afã de intervenção, de 'agir sobre', é legitimado por sua conexão com o 'compreendido' ou 'aprendido', um conjunto de saberes depurado de qualquer perspectiva de devir e de qualquer disposição de reflexividade, porque visto como 'correto' ou 'melhor'. Com efeito, o 'agir sobre' é invocado como um agir instruído, informado pelo conhecimento da 'forma correta', da 'melhor maneira possível', do 'melhor procedimento' ou por uma 'boa visão'. Trata-se de um pressuposto do deslocamento mencionado, visto que, diversamente da libido sciendi - para a qual o fluxo das interrogações não se esgota, mas é apenas interrompido em um ponto, arbitrariamente, pela intenção subjacente a um empreendimento cognitivo singular -, para a libido dominandi ele se conclui em um ponto, investido da certeza cognitiva que assegura a certeza do projeto e da adequação dos meios para 'agir sobre' (Bauman, 1999).

Nessa concepção, o objetivo da aprendizagem é 'produzir um sujeito', munindo-o com os recursos cognitivos necessários para agir, ao mesmo tempo que objetiva ou produz como 'objetos' outros sujeitos. De um lado, encontramos 'o médico', seu "papel (...) na sociedade e a importância dele nesse meio" (S1), o sujeito cognoscente capaz de "relacionar a estrutura, os fatos e os acontecimentos sociais ao adoecimento" (S2), de escolher "o melhor procedimento" (S3), de "criar propostas e projetos EFETIVOS" (S4). É esse o sujeito (a subjetividade) que se pretende encontrar ao final do processo de aprendizagem. Do outro lado, encontramos 'a sociedade', 'a população', 'o paciente', 'o centro de saúde' ou 'o Sistema Único de Saúde', como objeto de conhecimento e de intervenção. Esses lugares inscritos no discurso permitem captar o sentido que os estudantes constroem para os termos 'saúde' e 'sociedade' (que dão nome à disciplina) a partir de sua experiência no primeiro ano de graduação.

'Sociedade' é o nome do 'outro': é o 'outro' da medicina, do médico, do 'eu', uma 'outridade' representada como uma multiplicidade de objetos mudos e passivos, objetos de conhecimento e de ação. Como tal, a 'sociedade' aparece sempre sob a rubrica da falta, da insuficiência ou dos 'defeitos': ora como um conjunto de 'necessidades epidemiológicas', de 'saneamento básico' ou de 'atendimento médico', ora como um campo institucional de ação, o Sistema Único de Saúde (SUS) ou as unidades básicas de saúde, igualmente carentes de intervenção corretiva, ora pulverizada e encarnada na figura do 'paciente', sempre hipossuficiente e passivo, à espera da intervenção salvadora do médico. Seja como determinado agregado social, seja como instituição ou como indivíduo, é sempre o 'outro' colocado na 'sala de espera', não sujeito, mas objeto, inscrito em um 'regime de representação' (Hall, 1996), antes de qualquer ação, gesto ou discurso por meio do qual se (auto)apresente como sujeito, em sua singularidade. 
É interessante observar que, mesmo quando a ênfase recai sobre dimensões culturais, tangenciando a questão da diversidade, domina essa mesma perspectiva objetivante e negativa dos 'outros sujeitos', reconduzidos do plural (cultural-existencial) ao singular, 'outro', sempre falto, epistemológica e praticamente. Como lemos em uma expectativa (S6), o "contato com a população" é percebido como útil para desenvolver habilidades para "garantir, no futuro, tratamento e medidas adequadas com base nos costumes, tradições e deficiências da população". Costumes e tradições são abordados nesse texto (como em outras expectativas) não como possibilidades e potencialidades para produção de saúde e cuidados, modos de ser, conhecer e agir que exprimem sentidos e estratégias de sujeitos singulares no manejo da saúde e da doença em suas circunstâncias particulares, mas como territórios de insuficiências a serem supridas pelo agente capacitado para criar medidas eficientes justamente por conhecer as 'deficiências da população'. Não se trata, portanto, de ignorar a existência da diversidade cultural, mas de, no quadro de uma distinção nítida entre sujeito da ação (o profissional detentor do saber eficiente, saber assumido como social e culturalmente 'neutro', exterior aos 'costumes e tradições') e objeto da ação (indivíduo ou população hipossuficiente, 'deficiente'), reconhecê-la e investigá-la para identificar possíveis barreiras ou dificuldades a serem superadas, assumindo uma atitude de condescendência desinteressada diante dos conteúdos e dinâmicas culturais que não representam entraves para a 'saúde'.

'Saúde' é o 'produto esperado da intervenção da medicina'. Com efeito, nas expectativas, 'saúde' aparece como algo que só pode ser pensado a partir das categorias da medicina institucionalizada/profissionalizada. É quase o seu segundo nome. Não deve surpreender, portanto, que, em três expectativas, haja uma confusão em torno do nome da disciplina, denominada 'medicina e sociedade'. 'Saúde' e 'medicina' emergem como termos intercambiáveis.

Um dos efeitos dessas concepções de 'saúde' e 'sociedade' é que a medicina (localizada no polo do sujeito) é postulada como algo que está 'fora' da 'sociedade' (localizada no polo do objeto). A medicina (e os saberes adjacentes da área das ciências da saúde) aparece como um saber 'não situado' social e culturalmente, um conhecimento objetivo e universal; e o médico ou o profissional de saúde, como um sujeito que age ou deveria agir em função desse saber. Como observa Laplantine (1991, p. 41), no campo dos saberes em saúde, a medicina científica ocidental "habitualmente se apresenta como situante, ou seja, dispensado de ser situado". Os alunos repõem, portanto, em suas afirmações, essa representação 'habitual', que 'reterritorializa', no campo da saúde, a perspectiva do 'ponto zero' das epistemologias 'coloniais' (Castro-Gomez, 2005), que é aquela de um ponto de vista que se representa como não tendo ou não sendo um ponto de vista, ocultando sua perspectiva social e culturalmente situada sob as rubricas da universalidade ou objetividade (axiologicamente neutra). 
'Sociedade' designa, nesse sentido, um território saneado de 'agência'5 (pelo menos no campo da saúde), enquanto 'saúde' designa um território saneado de 'pluralidade'. A 'sociedade' é o 'outro' (no singular) que os agenciamentos legítimos em 'saúde' devem reconduzir aos marcos reguladores (conceituais e prático-instrumentais) dos saberes válidos ('corretos' ou 'melhores') em saúde. A ação em saúde é a prerrogativa de sujeitos que já não falam a partir de sua própria diferença (social e cultural), mas a partir da autoridade de saberes produzidos no território epistemológico e prático unificado pela medicina científica institucionalizada, concebida como 'uma' pelo esvaziamento de sua 'pluralidade epistemológica interna' (ilusão de convergência de perspectivas e objetivos epistemológica e politicamente alternativos presentes no campo da medicina científica) e como 'o único conhecimento válido no campo da saúde pela desvalorização da pluralidade epistemológica externa' (não reconhecimento de outros conhecimentos, dotados de outros critérios de validade, outros objetivos, escalas, perspectivas e, portanto, 'objetos', mundos possíveis). ${ }^{6}$ Agência e pluralidade encontram-se, portanto, em polos opostos no campo da ação em saúde. A agência aparece como um problema de tradução prático-instrumental de saberes socialmente legitimados; a pluralidade, como um problema de gestão. Ou nem isso.

Com efeito, outra concepção captável nas expectativas é a de que esse 'objeto', a 'sociedade', é algo tão simples que pode ser apreendido de uma vez, por meio do contato direto com um fragmento dela, gerando um aprendizado replicável em qualquer contexto. O pressuposto dessa abordagem é a supressão da diversidade, da incerteza e da ambivalência da experiência social, a redução de seu campo de possíveis e da pluralidade de seus agentes e sua formulação como uma 'coleção de problemas' (Bauman, 1999) reconhecidos como tais em vista de um repertório de 'soluções' aprovadas pelo corpo de especialistas. A complexidade, como Deus para Descartes, se torna uma hipótese desnecessária: o que o contexto de ensino em torno do tema 'saúde e sociedade' deve propiciar é a possibilidade de se apropriar cognitivamente da 'sociedade' como um conjunto de dimensões focalizadas (identificadas como dignas de observação), segmentadas (abordáveis em seu isolamento, como objeto de conhecimento e de ação), semanticamente filtradas e traduzidas (apresentadas em termos que facilitem sua conexão com os saberes biomédicos), e convertidas, assim, em problemas 'técnicos' específicos, que exigem respostas 'técnicas' específicas.

Não estranha assim que, em algumas expectativas, os verbos 'aprender' ou 'compreender' sejam substituídos pelo 'mostrar'. A expectativa é de que a disciplina "mostre, mais praticamente, a realidade dos centros de saúde" ou que as atividades da disciplina "mostrem um pouco da relação médico-paciente e da relação médico-equipe profissional" ou possam "mostrar muito mais a respeito da medicina e do dia a dia do médico". O processo de aprendizado é aqui equiparado ao de uma disciplina de anatomia humana. O objetivo, 
analogamente concebido, de aprender "a relacionar a estrutura, os fatos e os acontecimentos" converge didaticamente para o método do 'mostrar' e se encerra com o aprendizado de modos procedimentalizados de intervir sobre 'problemas' - em um caso, problemas de morfofuncionalidade do corpo biológico e que requerem terapias específicas; no outro, um conjunto de problemas médico-sanitários prevalentes no corpo social e que demandam a identificação de "formas de mudar a sociedade para prevenir ou curar doenças".

O paralelo, entretanto, não é completamente exato. Há uma hierarquização latente entre as disciplinas da grade curricular, sutilmente indiciada nas reivindicações, presentes em algumas expectativas, de que a disciplina 'saúde e sociedade' seja "leve", "aplicada e prazerosa", didaticamente orientada para "algo mais prático do que ler muitos textos", em contraste com o "curso pesado", que "concentra uma carga enorme de disciplinas que se aprendem com longas leituras". Nas disciplinas biomédicas, como as de anatomia humana, aulas e leituras teóricas são mais facilmente admitidas como necessárias para desenvolver uma expertise de interpretação, capacidade decodificadora, para conferir inteligibilidade ao que é 'mostrado' nas aulas 'práticas'. Por isso, o caráter "pesado" e o aprendizado com "longas leituras" não são questionados no contexto dessas disciplinas. Espera-se, ao contrário, que as disciplinas 'saúde e sociedade' se desenvolvam como espaços de descompressão dentro do "curso pesado". O que justifica essa expectativa diferenciada é justamente a concepção de que os temas e conteúdos dessas disciplinas são tão facilmente apreensíveis por meio da observação direta ou tão óbvios que requerem pouca ou nenhuma mediação teórica: um conhecimento corriqueiro que apenas ganha relevância no campo da saúde por sua conexão com os saberes expertos aprendidos nas outras disciplinas (biomédicas). A presença dessa concepção não parece ser um fenômeno localizado (Benbassat et al., 2003).

Nessa perspectiva, as disciplinas do módulo 'saúde e sociedade' devem, antes de tudo, favorecer 'o contato' dos estudantes com a 'sociedade', permitindo que eles vivenciem e desenvolvam atividades em contextos concretos de aplicação dos saberes expertos aprendidos em outras disciplinas. As atividades em serviços de atenção básica aparecem aqui como estratégias didático-pedagógicas válidas, identificadas como viáveis a partir do repertório de experiências dos estudantes no primeiro ano, no módulo 'ações de saúde pública'. A demanda de 'mais' atividades em centros de saúde e 'mais' experiências concretas de intervenção nesses contextos é comum a quase todas as expectativas, variando de acordo com o interesse do estudante por esse ou aquele contexto de 'contato' ou por essa ou aquela modalidade de intervenção. Assim, enquanto um estudante espera "acompanhar mais consultas médicas", outra deseja "estar mais próxima da realidade e cotidiano dos usuários, para que eu possa entender de forma efetiva suas carências e aflições e solucionar os problemas que estiverem ao meu alcance enquanto profissional médico", 
ao passo que um terceiro espera que a disciplina possa mostrar "pequenas coisas que podemos fazer para melhorar o posto de saúde", e assim por diante.

Após essas considerações, podemos dizer que as expectativas anunciam, em seu conjunto, uma proposta pedagógica coerente, alinhada por uma concepção utilitária e funcional ou, mais especificamente, 'ortopédica', no sentido dado ao termo por Santos (2008). Segundo a elaboração deste autor, o 'pensamento ortopédico' se refere a uma dupla redução do campo epistemológico - que passa a ser o campo da ciência como único conhecimento válido - e das possibilidades de tematização dos problemas existenciais - conceitual e analiticamente reconvertidos para os limites dos problemas apresentados pela ciência ou dos problemas para os quais ela oferece resposta. A proposta pedagógica subjacente às expectativas é articulada no âmbito dessa dupla redução, conectando aprendizagem e desejo de intervenção no sentido de 'agir sobre', no quadro de uma perspectiva em que a finalidade do processo de aprendizagem em 'saúde e sociedade' é a aquisição de competências para conectar a 'sociedade', concebida como multiplicidade de problemas não resolvidos, a soluções já disponíveis ('corretas' ou 'melhores'), endossadas pela 'saúde' (medicina científica e saberes adjacentes autorizados). Em outras palavras, o objetivo pedagógico visado é a aquisição de competência para localizar problemas em vista da capacidade disponível (isto é, autorizada) de fornecer soluções, o que pressupõe a invisibilização ou o descarte, como irrelevantes, dos possíveis saberes, sentidos, desejos, razões e sujeitos que, extrínsecos à 'saúde' definida como campo ostensivo de aplicação de saberes autorizados em saúde, questionem o direito e a autoridade dessa imposição (não admitida como tal) do campo de problemas e soluções.

A inscrição nesse contexto de dupla redução do 'pensamento ortopédico' favorece a compreensão de uma última dimensão do material para a qual pretendemos chamar a atenção: um interesse subjacente de colher, no curso da disciplina, orientações e instrumentos para construir 'uma identidade' como profissional e mesmo o sentido de sua busca existencial na carreira médica. De maneira explícita, um estudante espera que a disciplina seja capaz de "nos dar força e ânimo perante o curso pesado, mostrando o porquê de termos escolhido medicina". Não se trata, certamente, da expectativa de uma reflexão crítica ou problematizadora da medicina, da 'medicalização social' ou do 'papel do médico', nem de uma abordagem que 'devolva' o estudante ao papel de agente responsável por suas escolhas e suas consequências em um contexto plural e saturado de ambivalências axiológicas e práticas. Pelo contrário, supondo ser possível encontrar, em um mundo 'saneado' de incertezas, critérios extrapessoais para a construção de uma identidade (Bauman, 1999), o que se espera é libertar-se da necessidade angustiosa de construir por si mesmo um papel e de se posicionar. Ora, se a conexão entre problemas e soluções pode ser articulada de maneira não problemática com base no aprendizado 
da 'forma correta' ou da 'melhor maneira', o problema representado pela angústia e pela insegurança em relação à escolha profissional e à construção de uma identidade como médico pode igualmente encontrar uma resposta não problemática no âmbito de uma disciplina.

O que gera estranheza aqui é que essa demanda se dirige a cientistas sociais no âmbito de uma disciplina sobre 'saúde e sociedade'. É esse tipo de ambivalência que nos parece poder ser abordada mediante a análise daquela outra parte material (as avaliações) já referida. Aqui, como foi dito, o interesse era explorar o conteúdo da 'lógica' que se repõe nas expectativas e que reflete determinada intencionalidade estratégica no uso desse 'lugar' de enunciação. As expectativas revelam, antes de tudo, um esforço de adesão a discursos socialmente hegemônicos e, particularmente, àqueles dominantes no processo formativo dos alunos dentro da instituição; não permitem apreender as formas de resistência ou as diferenças dos sujeitos em relação à 'lógica' expressa. Isso não quer dizer que essa 'lógica' não tenha nenhuma efetividade no âmbito da subjetividade dos estudantes, incidindo sobre seus modos de pensar e agir, mas que essa incidência pode variar muito de indivíduo para indivíduo e que esses sujeitos podem ser internamente mais plurais e ambivalentes (e, por que não, mais contra-hegemônicos) do que a 'expressão da lógica' presente nas expectativas sugere.

\section{Considerações finais}

Na seção anterior, exploramos o conteúdo da 'lógica' presente nas expectativas. Nesta seção, o que nos propomos é refletir sobre o contexto de sua construção, seguindo duas pistas importantes fornecidas pela análise desse material: a ausência de qualquer referência às ciências sociais e a construção das expectativas por referência retrospectiva à experiência no módulo 'ações de saúde pública'.

Em sua configuração hegemônica, a medicina lida, na melhor das hipóteses, com o 'social' e o 'cultural' como um resíduo indesejável da prática médica, que, embora se realize como aplicação de saberes expertos a casos específicos, opera diretamente sobre material humano, dependendo, em muitos casos, da adesão e da participação do 'outro' para que tal aplicação seja possível. Em todo caso, como na parábola 'médico-higienista' criada por Monteiro Lobato (1961), ${ }^{7}$ o 'social' e o 'cultural' são incluídos para favorecer a adesão do Jeca Tatu à ciência médica e a suas prescrições, como condição de realização do seu milagre. No entanto, o pressuposto de seu constructo epistemológico (continuamos a falar aqui da configuração hegemônica) continua a ser "a ilusão de uma ruptura entre a doença e o social" (Laplantine, 1991, p. 225).

Pode-se dizer, assim, que a forma hegemônica (biologicista) de representação da profissão médica a que os estudantes de medicina estão expostos 
antes de seu ingresso na graduação não os predispõe, para dizer o mínimo, a identificar um lugar ou atribuir relevância às ciências sociais para essa profissão. O próprio itinerário do estudante como aluno secundarista pretendente à carreira médica tende a descartar a possibilidade de perceber tal relevância.

Os 'guias' e manuais brasileiros a que os estudantes recorrem, frequentemente, para se orientar em sua escolha profissional representam a medicina como uma ciência biológica aplicada à saúde humana ou simplesmente como uma carreira da grande área de 'biológicas' - embora, seguindo a atual classificação de 'áreas de conhecimento' da Coordenação de Aperfeiçoamento de Pessoal de Nível Superior (Capes), alguns 'guias' tenham começado a apresentar a medicina como uma profissão da grande área das ciências da saúde. De qualquer modo, os processos seletivos para ingresso nas faculdades de medicina do país priorizam a verificação de conhecimentos físico-químico-biológicos compatíveis com o modelo atual da educação básica. Tal prática reproduz uma tendência que remonta ao início dos anos 1960, quando o vestibular de medicina passa a compreender apenas as provas de física, química e biologia (Ribeiro Netto, 1985). Atualmente, para ingresso no curso de Medicina, o vestibular da Unicamp atribui peso três para biologia e língua portuguesa e literatura; peso dois para matemática, física e química; e peso um para geografia e história. Essa valoração de saberes invoca uma determinada representação da medicina para a qual as ciências sociais parecem pouco relevante.

O sentido de 'menor relevância' é reforçado após o ingresso no curso de medicina, quando o estudante se depara com uma grade curricular em que as disciplinas biomédicas e de prática clínica (por dedução estruturadas por saberes biomédicos) dominam o conjunto da formação, com um corpo docente quase exclusivamente composto por profissionais formados em medicina. O contexto e a dinâmica institucionais, de modo geral, parecem contribuir para a invisibilização das ciências sociais no curso de medicina. Com efeito, não é difícil encontrar na literatura nacional e internacional sobre ensino de ciências sociais - em instituições de graduação em medicina - referências à falta ou à fragilidade da 'inserção' ou 'integração' das ciências sociais no currículo dos cursos de medicina (Nunes, 1978; Nunes et al., 2003; Barros e Nunes, 2009; Barros, 2014; Benbassat et al., 2003; Satterfield et al., 2010; Litva e Peters, 2008). A extensão da carga horária das disciplinas orientadas por abordagens das ciências sociais e a localização dessas disciplinas exclusivamente nos anos pré-clínicos da formação são apontadas como dimensões dessa fragilidade, o que contribui para a construção de um sentido de irrelevância das ciências sociais para a formação médica.

No contexto brasileiro, a ambivalência do modo de 'inserção' das ciências sociais na organização curricular pode ser captada já na redação das Diretrizes Curriculares Nacionais do Curso de Graduação em Medicina. Na resolução de 2001 (Brasil, 2001), ainda em vigor no ano em que coletamos as expectativas 
aqui analisadas, a indicação da necessidade de "dominar os conhecimentos científicos básicos da natureza biopsicossocial-ambiental subjacentes à prática médica" como competência profissional específica, ou da necessidade de introduzir, como conteúdos essenciais do desenvolvimento curricular, a “compreensão dos determinantes sociais, culturais, comportamentais, psicológicos, ecológicos, éticos e legais, nos níveis individual e coletivo, do processo saúde-doença", é traduzida concretamente na vaga referência à promoção da 'interdisciplinaridade', sem qualquer alusão explícita às ciências sociais.

Na resolução de 2014 (Brasil, 2014), que a substituiu, há uma significativa mudança em relação a esse aspecto, incluindo uma referência direta às 'ciências humanas e sociais', convidadas a ocupar a posição de "eixo transversal na formação do profissional com perfil generalista". Essa disposição mais clara de valorização das ciências sociais deve ser enfatizada. Entretanto, não se deve ignorar que a vagueza da resolução anterior é reposta na forma da exigência específica de "criar oportunidades de aprendizagem, desde o início e ao longo de todo o processo de graduação", sem qualquer menção ao sentido dessa aprendizagem e a estratégias concretas para sua implementação.

Na prática, independentemente da intencionalidade subjacente às novas diretrizes, a referência à 'transversalidade', como ocorreu com a 'interdisciplinaridade', pode traduzir-se em formas de (pseudo)incorporação das ciências sociais, mais decorativas que reais. Os dois termos podem ser invocados para não conceder nenhum lugar efetivo às ciências sociais no desenvolvimento curricular, cujos conteúdos/abordagens são assumidos como algo que 'já é feito', 'já é discutido' ou 'está implícito' no modo atual de condução da graduação em Medicina.

É em face desse quadro mais geral que devemos interpretar o fato de que, ao ingressarem no módulo 'saúde e sociedade', as únicas referências dos estudantes para construírem suas expectativas em relação a ele são tomadas retrospectivamente da experiência com as disciplinas do módulo 'ações de saúde pública' ${ }^{8}$ Claro que não faltam, para os estudantes, razões plausíveis para sustentar a perspectiva da continuidade: são módulos do mesmo departamento; alguns profissionais da área de ciências sociais aplicadas à saúde atuam como docentes nos dois módulos; em sua codificação na Diretoria Acadêmica da universidade, as disciplinas dos dois módulos são serializadas.

No entanto, isso não explica tudo. Entre os alunos pertencentes aos distintos anos do curso de medicina, há uma intensa circulação de informações (com valorações embutidas) acerca das disciplinas e docentes, o que, em geral, parece possibilitar a construção de expectativas mais ou menos realistas a respeito dos conteúdos, abordagens, metodologias e sistemas de avaliação das várias disciplinas, permitindo que os estudantes criem estratégias específicas em sua relação com cada uma. Isso, contudo, não ocorre da mesma maneira em relação ao módulo de 'saúde e sociedade', uma vez que as expectativas 
não trazem elementos do programa de suas disciplinas realizadas em anos anteriores, e sim da experiência com outro módulo. Pode-se supor, portanto, que haja outros dispositivos operando entre os estudantes e que contribuem para o apagamento dos conteúdos e discussões diferenciais do módulo.

No momento, com base no material investigado, não podemos avançar muito na discussão acerca de tais dispositivos e processos. Podemos, no entanto, afirmar que a ferramenta pedagógica dos 'projetos de intervenção', que estrutura quase toda a proposta da segunda disciplina de 'ações de saúde pública', tem um efeito pedagógico-formativo que representa um grande desafio para o módulo 'saúde e sociedade'. Com efeito, gera um afã de intervenção que precede e desfigura a própria disposição de compreender e conhecer, que, além de qualquer possível sentido prático imediato, pode ser erótica, estética e existencialmente significativa (Maffesoli, 1998). Como vimos na seção anterior, a experiência nesses projetos tem desembocado em um lugar conceitual e prático problemático, o que reforça os reducionismos do 'pensamento ortopédico' e as distinções 'coloniais' entre sujeitos e entre saberes e práticas subjacentes a ele.

Assim, concluímos este artigo com a percepção de um desafio que deve sensibilizar todos os educadores no campo da saúde: como desconstruir essa concepção 'ortopédica' e 'colonial' de 'intervenção' dentro da qual os profissionais atuantes no campo da saúde têm sido formados? Não pretendemos aqui propor respostas a essa indagação, mas uma reflexão sobre alguns pressupostos para tal proposição.

Em primeiro lugar, a desconstrução pretendida implica reconhecer o caráter histórico, cultural e socialmente 'localizado' ou contextual da episteme médica institucionalizada. Trata-se, como proposto por Santos, Menezes e Nunes (2004, p. 49-50), na esteira do físico Lévy-Leblond, de "(re-)pôr a ciência na cultura", ou seja, de "restituir às ciências a sua espessura cultural e histórica, recuperar a sua história e examinar as suas implicações no mundo". Sem essa perspectiva alargada, é impossível captar integralmente o caráter intrinsecamente problemático da conformação (hegemonicamente) intervencionista da medicina institucionalizada. Enquanto a pressuposição de sua neutralidade e superioridade permanecer inabalada, é possível continuar a sustentar seu monopólio sobre as práticas epistemológicas e sociais em saúde e, consequentemente, a relacionalidade (hierarquizada) entre especialistas e não especialistas que ele fundamenta (expressa em um conjunto variado de dicotomias e matizes de hierarquização, tais como conhecer/ignorar, inventar-inovar/difundir-receber, produzir/consumir, atuar/ receber, recomendar/seguir etc.).

Outro pressuposto dessa desconstrução é o reconhecimento do que Santos (2008) denomina 'pluralidade epistemológica do mundo'. No caso em tela, trata-se de reconhecer a existência de outras matrizes epistemológicas (atualmente 
invisibilizadas, marginalizadas ou integradas perifericamente/colonialmente, como práticas complementares ou suplementares, à medicina institucionalizada) no campo da saúde, de outros modos de conceber e produzir saúde, de outras práticas e relacionalidades na produção de cuidados, implicados em e incidindo retroativamente sobre diferentes modos de ser e viver. A própria perspectiva de "(re-)pôr a ciência na cultura" depende desse reconhecimento, uma vez que não é possível se saber "localizado" exclusivamente em relação a si mesmo, mas apenas em uma "comparação de multiplicidades", o que Castro (2007, p. 101) dilucida como um processo de "implicação-explicação relacional" de multiplicidades orientado para "determinar seus modos característicos de divergirem, suas distâncias internas e externas". O desafio posto não tem nada a ver com rejeitar a medicina científica ou desvalorizar suas eficácias específicas, mas sim reconhecer as especificidades (contextuais) de suas eficácias - o que implica falar em possibilidades e limites específicos em uma 'comparação de multiplicidades' - e ativar as potencialidades (outras eficácias específicas, com outras possibilidades e outros limites) da 'pluralidade epistemológica' no campo da saúde.

Esse reconhecimento e essa ativação só podem ser conduzidos em processos complexos de experimentação social desencadeados em um terreno "de multiplicidades planas" ou "acentradas" (Castro, 2007) e de conexões produtivas (geradoras de novos campos de subjetivação/objetivação) de agências e agentes epistêmicos diversos. Nesse sentido, inserem-se na tarefa de "multiplicar o número de agências que povoam o mundo" (Latour apud Castro, 2007, p. 96). Isso significa que são necessários processos de desinstitucionalização e de institucionalização (aberta à presença de uma potência instituinte permanente) que permitam esse 'povoamento' no campo da saúde em geral e da formação médica em particular, uma abertura para outros agentes, outras epistemologias e para a possibilidade de novas conexões produtivas no campo da saúde e da medicina.

Acreditamos que a transversalidade das ciências humanas e sociais ao longo de toda a formação médica, no sentido proposto pelas DCNs (Brasil, 2014), poderia cumprir um papel importante nesse processo. O que se propõe transversalizar (talvez aqui, porém, em sentido diferente do proposto pelas DCNs) não é a atuação de uma área/departamento, nem mesmo a presença de um campo acadêmico específico de saber, de seus temas e conteúdos, mas a reflexividade que permita perceber os 'sujeitos' e 'objetos' postos (inclusive, o próprio biológico) pelos agenciamentos em saúde como sociais e culturais e, portanto, a aprendizagem e a prática em medicina como a possibilidade permanente de serem outras, no exercício constante de um "imaginário do 'alter"' (Castro, 2012, p. 155), na "comparação de multiplicidades". Em poucas palavras, um exercício de 'alteridade' que só é possível pela agência de uma multiplicidade de sujeitos, não somente de diversos campos acadêmicos de saber (além da medicina e das ciências sociais), mas também de diversos contextos não acadêmicos de saber. 
Resumen La investigación presentada en este artículo tiene el objetivo de investigar la 'expresión de cierta lógica' dominante en la formación médica a través del análisis de las expectativas de estudiantes de una institución de enseñanza de la medicina en relación a una disciplina concentrada en temas/ reflexiones de las ciencias sociales en la salud y coordinada por los científicos sociales. El material analizado es compuesto por las expectativas de 72 estudiantes recogidas a través de una invitación a escribir libremente sin tener que identificarse a sí mismos, sobre lo que esperan en relación con la disciplina. El análisis de este material revela el predominio de discursos y experiencias educativas que contribuyen a la producción de un diseño 'instrumental' y 'colonial' de la práctica médica y nos permite entender algunas de las dificultades para el ejercicio crítico y reflexivo de las ciencias sociales en la educación médica. La identificación de la necesidad de deconstruir esa 'lógica', el artículo no concluye con una propuesta pedagógica específica, sino que indica la necesidad de un proceso de desinstitucionalización/institucionalización dirigida a la 'descompresión' epistémica en el campo de la salud, en general, y la educación médica, en particular, una apertura a otros agentes, otras epistemologías y a la posibilidad de nuevas conexiones productivas en el campo de la salud y la medicina Palabras-clave ciencias sociales; educación medica; colonialidad.

\section{Colaboradores}

Todos os autores participaram igualmente, em todas as etapas, da produção do artigo.

\section{Notas}

${ }^{1}$ Universidade Estadual de Campinas, Faculdade de Ciências Médicas, Departamento de Saúde Coletiva, Campinas, São Paulo, Brasil.

$<$ rafonso@fcm.unicamp.br>

Correspondência: Rua Tessália Vieira de Camargo, 126, Cidade Universitária Zeferino Vaz, CEP 13083-887, Campinas, São Paulo, Brasil.

${ }^{2}$ Universidade Estadual de Campinas, Faculdade de Ciências Médicas, Departamento de Saúde Coletiva, Campinas, São Paulo, Brasil.

$<$ aneirosfernandez@gmail.com>

${ }^{3}$ Universidade Estadual de Campinas, Faculdade de Ciências Médicas, Departamento de Saúde Coletiva, Campinas, São Paulo, Brasil.

$<$ nelfel@uol.com.br>

${ }^{4}$ Universidade Estadual de Campinas, Faculdade de Ciências Médicas, Departamento de Saúde Coletiva, Campinas, São Paulo, Brasil.

$<$ jluporini10@hotmail.com>

${ }^{5} \mathrm{O}$ termo 'agência' refere-se à capacidade de produzir efeitos, afecções e conexões/relações, desencadeando processos que constituem simultaneamente as subjetividades e objetividades 
mobilizadas nessa produtividade. A concepção que atravessa as expectativas dos alunos suprimiria, segundo nossa análise, essa potência criadora do 'lado' dos 'não especialistas' (definidos como tais em relação à medicina científica institucionalizada) no campo da saúde. Essa supressão decorre de uma perspectiva de eficácia que se fundamenta, em primeiro lugar, na noção de univocidade da expertise que permitiria a 'ação eficaz', assumindo como ponto pacífico as intencionalidades/valores (o para-quê) que definem o sentido da eficácia, bem como seu 'objeto' e, em segundo lugar, na projeção da diferença (própria da racionalidade tecnicista) entre 'o que age' (sujeito) e 'o que é agido' (objeto) para o campo da própria relacionalidade entre sujeitos (sujeitos que agem $=$ especialistas / sujeitos sobre os quais se age = não especialistas).

${ }^{6}$ As noções de pluralidade epistemológica interna e pluralidade epistemológica externa foram emprestadas de Santos (2008).

${ }^{7}$ Como observam Lima e Hochman (2000, p. 322), “a ressurreição do Jeca Tatu é narrada na forma de uma parábola dirigida às crianças. Ao passar a acreditar na ciência médica e a seguir suas prescrições, o personagem transforma-se". Mas a conversão do Jeca Tatu à ciência médica, que precede sua "ressurreição" colonizada, não se fez sem a mediação (colonizadora) do "sêo doutor" como tradutor didático de conhecimentos médicos para os termos da cultura "limitada" do "caboclo", inclusive por meio de experimentos práticos, para que "não duvide mais do que a Ciência disser" (Lobato, 1961, p. 335). Ao Jeca Tatu, representante do território arrasado, invisível, de todas as matrizes culturais concorrentes à medicina científica ocidental, cabe apenas não duvidar mais "do que a Ciência disser".

${ }^{8} \mathrm{O}$ módulo 'ações de saúde pública', composto por duas disciplinas (MD142 e MD242) ministradas por equipe multidisciplinar, no primeiro ano do curso de graduação, tem como objetivo a introdução do aluno no campo da saúde coletiva, com ênfase em temas relacionados à estrutura e à organização do Sistema Único de Saúde. No contexto a que se refere à pesquisa aqui apresentada, o módulo pressupunha a realização de um projeto de intervenção (de prevenção ou promoção da saúde) pelos alunos (divididos em subgrupos) com unidades da atenção básica de Campinas. O módulo 'saúde e sociedade', composto por duas disciplinas (MD342 e MD442) ministradas por docentes ou profissionais com formação em ciências sociais, no segundo ano do curso, visa, de modo geral, introduzir conteúdos e discussões das ciências sociais que oportunizem exercícios crítico-reflexivos em relação ao campo da saúde.

\section{Referências}

BARROS, Nelson F. O ensino das ciências sociais em saúde: entre o aplicado e o teórico. Ciência \& Saúde Coletiva, Rio de Janeiro, v. 19, n. 4, p. 1.053-1.066, 2014.

BARROS, Nelson F. et al. Resposta em escala seguida de justificativa: uma avaliação triangulada. In: CATRIB, Ana Maria F.; BRASIL, Christina C. P.; CARLO, Daniele A. O. (orgs.). Avaliação de processos educacionais em saúde: tendências e inovações. Fortaleza: EdUECE, 2016.
BARROS, Nelson F.; NUNES, Everardo D. Sociologia, medicina e a construção da sociologia da saúde. Revista de Saúde Pública, São Paulo, v. 43, n. 1, p. 169-175, 2009.

BAUMAN, Zygmunt. Modernidade e ambivalência. Rio de Janeiro: Jorge Zahar, 1999.

BENBASSAT, Jochanan et al. Overcoming barriers to teaching the behavioral and social sciences to medical students. Academic Medicine, New Mexico, v. 78, n. 4, p. 372-380, 2003. 
BRASIL. Conselho Nacional de Educação. Câmara de Educação Superior. Resolução CNE/ CES n. 4, de 7 de novembro de 2001. Institui diretrizes curriculares nacionais do curso de graduação em medicina. Diário Oficial da União, Brasília, n. 215, p. 38, 9 nov. 2001, Seção 1.

BRASIL. Ministério da Educação. Conselho Nacional de Educação. Câmara de Educação Superior. Resolução CNE/CES n. 3, de 20 de junho de 2014. Institui diretrizes curriculares nacionais do curso de graduação em medicina e dá outras providências. Diário Oficial da União, Brasília, n. 117, p. 8-11, 23 jun. 2014, Seção 1.

CASTRO, Eduardo V. "Transformação" na antropologia, transformação da "antropologia". Mana: Estudos de Antropologia Social [online], Rio de Janeiro, v. 18, n. 1, p.151-171, 2012. Disponível em: <http:// www.scielo.br/scielo.php?script=sci_arttext\& pid=S0104=93132012000100006-\&lng=en\&nrmiso >. Acesso em: 20 maio 2017.

CASTRO-GOMEZ, Santiago. La poscolonialidad explicada a los niños. Bogotá: Universidad del Cauca, Instituto Pensar, 2005.

FERNANDEZ, Juan C. A. Avaliação de políticas públicas como possibilidade de inclusão. In: FERNANDEZ, Juan C.; CAMPOS, Marisa; CAZZUNI, Dulce H. (orgs.). Avaliar para compreender: uma experiência na gestão de programa social com jovens em Osasco, SP. São Paulo: Hucitec; Cepedoc Cidades Saudáveis, 2008. p. 119-146.

HALL, Stuart. The West and the rest: discourse and power. In: HALL, Stuart et al. (orgs.). Modernity: introduction to the modern societies. Oxford: Blackwell, 1996. p. 185-227.

LAPLANTINE, François. Antropologia da doença. São Paulo: Martins Fontes, 1991.

LIMA, Nísia T.; HOCHMAN, Gilberto. Pouca saúde, muita saúva, os males do Brasil são...: discurso médico-sanitário e interpretação do país. Ciência \& Saúde Coletiva, Rio de Janeiro, v. 5, n. 2, p. 313-332, 2000.
LITVA, Andrea, PETERS, Sarah. Exploring barriers to teaching behavioral and social sciences in medical education. Medical Education, v. 42, n. 3, p. 309-314, 2008.

LOBATO, Monteiro. Mr. Slang e o Brasil e problema vital. São Paulo: Brasiliense, 1961.

MAFFESOLI, Michel. Elogio da razão sensivel. Petrópolis: Vozes, 1998.

NUNES, Everardo D. Análise de alguns modelos utilizados no ensino das ciências sociais nas escolas médicas: bases teóricas. Revista de Saúde Pública, São Paulo, v. 12, n. 4, p. 506-515, 1978.

NUNES, Everardo D. et al. O ensino das ciências sociais nas escolas médicas: revisão de experiências. Ciência \& Saúde Coletiva, Rio de Janeiro, v. 8, n. 11, p. 209-225, 2003.

RIBEIRO NETTO, Adolpho. O vestibular ao longo do tempo: implicações e implicâncias. Seminário Vestibular Hoje. Brasília: MEC/ Sesu/Capes, 1985. <http://www.fcc.org.br/ pesquisa/publicacoes/es/artigos/116.pdf $>$. Acesso em: 25 maio 2016.

SANTOS, Boaventura S. A filosofia à venda, a douta ignorância e a aposta de Pascal. Revista Crítica de Ciências Sociais, Coimbra, v. 80, p. 11-43, 2008.

SANTOS, Boaventura S.; MENESES, Maria P. G.; NUNES, João A. Introdução: para ampliar o cânone da ciência - a diversidade epistemológica do mundo. In: SANTOS, Boaventura S. (org.). Semear outras soluções: os caminhos da biodiversidade e dos conhecimentos rivais. Porto: Afrontamento, 2004. p. 19-101.

SATTERFIELD, Jason M. et al. Creating an ideal social and behavioral sciences curriculum for medical students. Medical Education, v. 44, n. 12, p. 1194-1202, 2010.

Recebido em 05/07/2016. Aprovado em 23/03/2017. 